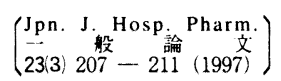

\title{
尿中ニコチン代謝物の定量によるタバコ煙暴露の評価と臨床応用
}

\author{
船越幸代 $* \dagger^{1}$, 小西敏夫 $\dagger^{1}$, 横手千秋 $\dagger^{1}$, 前田頼伸 $\dagger^{1}$, 大和浩之 $\dagger^{1}$, \\ 突合泉月 $\dagger^{1}$, 大宇根晃雅 $\dagger^{2}$, 津谷隆史 $\dagger^{2}$ \\ 中国労災病院薬骩部 $\dagger^{1}$, 同呼吸器科 $\dagger^{2}$
}

\section{The Assessment of Tobacco Smoke Exposure Based on the Presence of Metabolites of Nicotine in the Urine and its Clinical Application}

\author{
SACHIYO FUNAKOSHI ${ }^{*}{ }^{1}$, TOSHIO KONISHI $\dagger^{+}$, CHIAKI YOKOTE $\dagger^{1}$, YORINOBU MAEDA $\dagger^{1}$ \\ HIROYUKI YAMATO $\dagger^{+}$, SATSUKI TSUKIAI $\dagger^{1}$, TERUMASA OHUNE $\dagger^{2}$ and TAKAFUMI TSUYA $\dagger^{2}$ \\ Department of Pharmacy $\dagger^{1}$ and Pulmonary Division Department of Internal Medicine $\dagger^{2}$, \\ Chugoku Rosai General Hospital \\ $\left(\begin{array}{ll}\text { Received November 8, } 1996 \\ \text { Accepted February 25, } 1997\end{array}\right)$
}

It is well known that tobacco smoke causes the health risks not only for smokers but for non-smoker as well. We thus evaluated the urinary cotinine, content, which is a major metabolite of nicotine, by high-performance liquid chromatography (HPLC). Such a determination is considered to provide a useful objective assessment of exposre to tobacco smoke. Using the Previously described method, non-smokers in a typical company were thus found to appareutly demonstrate cotinine concentrations due to passive smoking, Furthermore we also determined the urinary cotinine in an asthma patient who could not stop smoking. The results indicated that the measurement of the urinary cotinine level by HPLC could be effective as a strong motivating factor to stop smoking and also to form a system of nosmoking support groups. In the future, such continuous study will enable us to approximate the effect of passive-smoking on a disease based on the measurement of the urinary cotinine level.

Key words - nicotin, cotinine, passive smoking, HPLC, system of supporting nosmoking

緒言

今日，喫煙者のみならず，受動喫煙による非喫 煙者の健康に及ぼすタバコの悪影響が社会問題に

†1,2 吳市広多賀谷 1-5-1 ; 1-5-1, Hirotagaya, Kure-shi, 737-01 Japan
なっている．血清や尿中などの Nicotine 代謝物の 定量は, ガスクロマトグラフィー法やラジオイム ノアッセイ法など数多く報告されている ${ }^{1-3)}$. 我々 は，タバコ煙の暴露量を客観的に把握するため, Nicotine の主要代謝物であり, 喫煙者の尿中に比 較的高濃度に存在し4), 生体内半減期が約20時間 
と長い ${ }^{5)}$ Cotinine に着目し，比較的簡便に測定で きる高速液体クロマトグラフ (HPLC) 法を用いた 定量法 ${ }^{6)}$ を検討した。また，喫煙者および受動 喫煙者の尿中 Cotinine 濃度を測定し，興味深い結 果が得られたので報告する。

\section{実験材料・方法}

\section{1. 試薬}

Cotinine は Aldrich Chem. Co. 製, その他の試薬 は和光純薬製のものを用いた。

\section{2. 測定方法}

分析は HPLC（TOSOH グラデュエートシステム） で行い,カラムは TSK-Gel ODS-80TM(TOSOH) を用いた。検出波長は UV260nm とし，移動相は acetonitril-methanol- $0.025 \mathrm{M} \mathrm{KH}_{2} \mathrm{PO}_{4}-0.01 \mathrm{M}$ sodium pentanesulphonate $(10: 2: 88: 0.43, \mathrm{~V} / \mathrm{V})$ を用 い, 流速 $1.0 \mathrm{ml} / \mathrm{min}$ とした.

\section{3 . 前処理操作}

武田らの方法 ${ }^{7)}$ に準拠し, 尿試料 $3 \mathrm{ml}$ に internal standard substance (I.S.)として norephedrin $50 \mu \mathrm{g}$ を加え， $3 \mathrm{NNaOH} 1 \mathrm{ml}$ を加え有機層に移行しゃ すくした後, chloroform（水飽和） $2 \mathrm{ml}$ を加え振 とう後, $3000 \times \mathrm{g}$ で 5 分遠心し有機層を採取し た。この操作を 3 回繰り返し, 採取した有機層を 水洗後, acetic acid $10 \mu \mathrm{l}$ を加え溶媒を減圧乾固 した.残渣を $250 \mu \mathrm{l}$ の移動相に溶媒し，分析試料 とした。

\section{4.対象および症例}

比較的喫煙者が多く,受動喫煙による暴露が予 想されるある職場において, 年齢24〜52歳の男性 15名（契煙者10名，非契煙者 5 名）の出勤時およ び退社時の尿を採取し，尿中 Cotinine 濃度を測定 した。 また, 外来患者の尿中 Cotinine 濃度も測定 した。尿中クレアチニンの定量は酵素法で行っ た.

\section{結果}

1. クロマトグラム

Blank 尿 (A) 及び Cotinine と I.S.を添加した
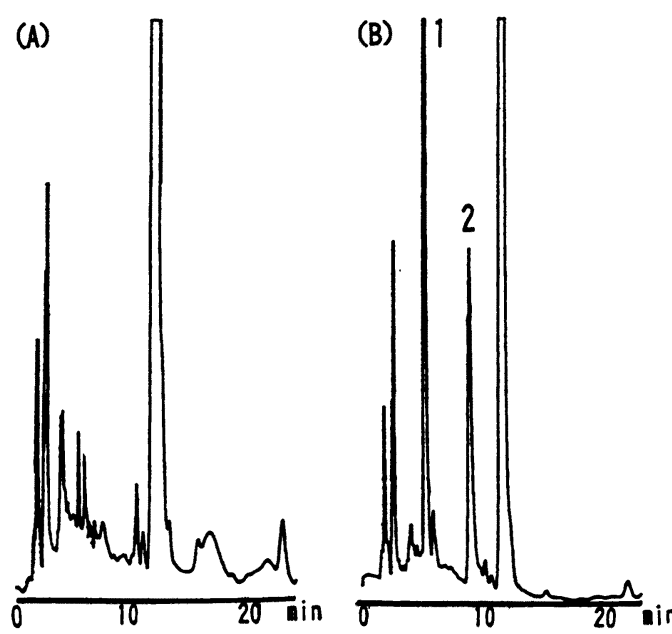

Fig. 1. Chromatograms by HPLC

(A) Blank urine from a non-exposed nonsmoker, (B) Blank urine added two compounds. $1=$ Norephedrine(I.S.), $2=$ Cotinine (400 ng/ml)

尿(B)のクロマトグラムを Fig. 1 に示した. I.S. の retention timeは5.58 分に, Cotinineのそれは 9.73分に認められた。

\section{2. 検量線}

Cotinine の検量線を Fig. 2 に示した. 50〜2000 $\mathrm{ng} / \mathrm{ml}$ の広い濃度範囲において, 濃度とピーク面 積比に良い直線性（ $\mathrm{r}=0.997 ）$ が得られた。また Cotinine の検出限界は $5 \mathrm{ng} / \mathrm{ml}$ であった。

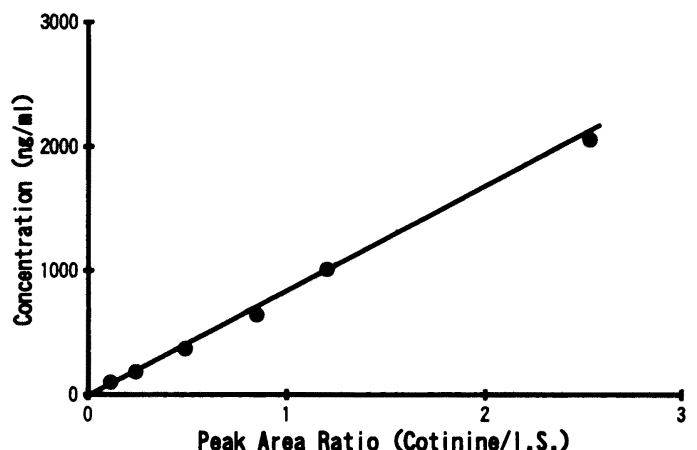

Fig. 2. Calibration Line of Cotinine $y=7.119+896.9 \times(r=0.997)$ 
Table 1. Recovery of Cotinine with the Proposed Procedure

\begin{tabular}{|c|c|c|c|c|c|c|c|}
\hline $\begin{array}{l}\text { conc. } \\
(\mathrm{ng} / \mathrm{m} \mid)\end{array}$ & 1 & 2 & 3 & 4 & 5 & $\begin{array}{c}\operatorname{mean} \pm S . D . \\
\text { (CV) }\end{array}$ & $\begin{array}{c}\text { arrecovery } \\
(x)\end{array}$ \\
\hline 200 & 191.2 & 194.9 & 193.9 & 207.8 & 209.6 & $\begin{array}{c}199.5 \pm 7.646 \\
(3.83 \%)\end{array}$ & $99.75 \pm 3.82$ \\
\hline (RRT) & 1.726 & 1.748 & 1.720 & 1.726 & 1.710 & $\begin{array}{c}1.726 \pm 0.012 \\
(0.695 \%)\end{array}$ & \\
\hline 400 & 389.5 & 390.0 & 406.1 & 404.9 & 383.2 & $\begin{array}{l}394.7 \pm 9.115 \\
(2.31 \%)\end{array}$ & $98.68 \pm 2.28$ \\
\hline (RRT) & 1.727 & 1.733 & 1.734 & 1.726 & 1.714 & $\begin{array}{c}1.727 \pm 0.007 \\
(0.405 \%)\end{array}$ & \\
\hline
\end{tabular}

RRT=relative retention time (Cotinine/I.S.)

\section{3. 回収試験}

Table 1 にBlank尿にCotinine (200ng/ml, 400ng/ $\mathrm{ml}$ )を添加したときの回収量を示した.いずれも， 回収率約 $99 \%$, 変動係数 (CV) $3 \%$ 前後と良好な 再現性が認められた。
4. ボランティアによる Cotinine 濃度の測定 ボランティア15名の尿中 Cotinine の測定結果を Table 2 に示した. 尿は部分尿であるため生体内 成分である尿中クレアチニン $(\mathrm{Cr})$ により Cotinine 濃度の補正を行った。また，Nicotine摂取量は，

Table 2. Analyses of Cotinine in Urine Sample of Volunteers by HPLC

\begin{tabular}{|c|c|c|c|c|c|}
\hline \multirow[b]{2}{*}{ No } & \multirow[b]{2}{*}{$\begin{array}{l}\text { Nicotin } \\
\quad(\mathbf{n g})\end{array}$} & \multicolumn{2}{|c|}{ to the office } & \multicolumn{2}{|c|}{ from the office } \\
\hline & & $\begin{array}{l}\text { Cotinine } \\
(\mathrm{ng} / \mathrm{m} \mathbf{l})\end{array}$ & $\begin{array}{c}\text { Cotinine } / \mathrm{Cr} \\
(\mathbf{n g} / \mathbf{m g})\end{array}$ & $\begin{array}{l}\text { Cotinine } \\
\text { (ng/m1) }\end{array}$ & $\begin{array}{c}\text { Cotinine } / \mathrm{Cr} \\
(\mathbf{n g} / \mathbf{m g})\end{array}$ \\
\hline \multicolumn{6}{|c|}{ Smoker } \\
\hline 1 & 19.5 & 2865 & 8005 & 3692 & 4193 \\
\hline 2 & 16.0 & 4087 & 1559 & 3094 & 2129 \\
\hline 3 & 16.0 & 3698 & 1428 & 3689 & 1585 \\
\hline 4 & 15.0 & 1255 & 659 & 666 & 1801 \\
\hline 5 & 15.0 & 2994 & 1044 & 3340 & 1719 \\
\hline 6 & 12.0 & 1957 & 972 & 1710 & 779 \\
\hline 7 & 10.0 & 549 & 318 & 433 & 196 \\
\hline 8 & 8.0 & 624 & 690 & 602 & 1316 \\
\hline 9 & 5.0 & 362 & 124 & 327 & 114 \\
\hline 10 & 4.9 & 677 & 213 & 632 & 200 \\
\hline \multicolumn{6}{|c|}{ Non-Smoker } \\
\hline 11 & - & 418 & 134 & 131 & 82 \\
\hline 12 & - & 174 & 136 & 106 & 111 \\
\hline 13 & - & 25 & 19 & 24 & 48 \\
\hline 14 & - & N. D. & N. D. & N. D. & N. D. \\
\hline 15 & - & N. D. & N. D. & N. D. & N. D. \\
\hline
\end{tabular}

N. D. =not detected 
アンケートにより 1 日の平均喫煙本数と喫煙タバ コの Nicotine 含有量より算出した.

喫煙者ではすべての尿に Cotinine が検出され， その濃度は，出勤時124～8005，退社時114～4193 Cotinine $/ \mathrm{Cr}(\mathrm{ng} / \mathrm{mg})$ であった。尿中 Cotinine 濃 度は，尿量など水分量により影響を受けやすく， 前述のようにクレアチニンによる補正を行った が，補正值においても，10人中 3 人において出勤 時濃度が退社時よりもかなり高值となっている. これは Cotinineの半減期が20時間と長い5)こと や就寝前喫煙など家庭での喫煙状態の関与による と考えられる。一方, 非契煙者においては 5 名中 3 名より Cotinine が検出され，その濃度は，出勤 時19 134, 退社時48〜111 Cotinine/ Cr (ng/mg) であった．検出された 3 名はいずれも喫煙経験が なく, 副流煙による受動契煙が示唆された。

\section{5. 相関性の検討}

Fig. 3 には,掑取 Nicotine 量と尿中 Cotinine 濃 度の相関性を示した. Nicotine 摂取量と尿中Cotinine 濃度には, r=0.83897と直線傾向が認めら れ，両者には相関関係があると思われる.

\section{考察}

近年，受動喫煙が社会問題となっている．今回 我々は HPLCによる尿中 Cotinine の定量法を検討 し，受動喫煙による暴露量を客観的に把握できる

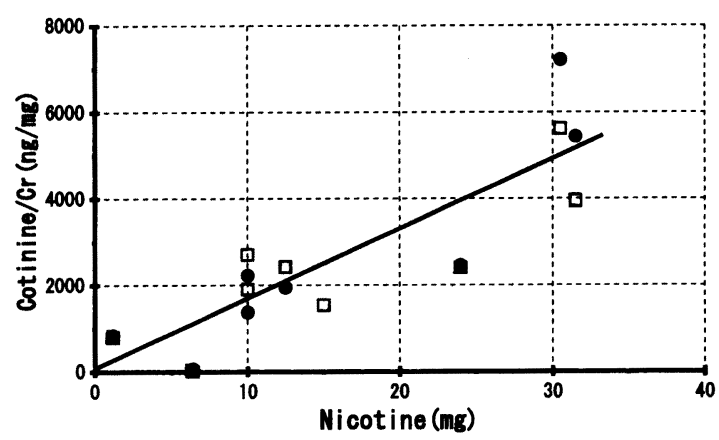

Fig. 3. Correlation between Cotinine in Urine and Nicotine Amount in Tabacco $\mathrm{Y}=-38.18+90.506 \mathrm{X}(\mathrm{r}=0.86897)$
かどうか検討した。非喫煙者で尿中に Cotinine が 検出されるのは個人の家庭や職場，公共の場所な ど生活環境でのタバコ煙の暴露によるものであ る. Cotinine 測定により喫煙が疾患に与える影響 がより認識できればと思われる，喫煙の健康に対 する悪影響が認められて以来，多くの禁煙法が研 究，開発されてきた。禁煙支援の方法にはニコチ ンガムやクロニジン投与などの薬理学的方法, Rapid-Smoking Therapy やリラクレーションとスト レス管理などの行動療法的アプローチ，また催眠 療法やカウンセリングなどがある，病院ではニコ レット等の Nicotine 含有ガムにより禁煙の援助を し，禁煙教室が開かれている。多くの人が禁煙の 悪影響を認識し，禁煙したいと思っているにもか かわらず，完全に禁煙することができず，禁煙し ても Nicotine による依存性のため再度喫煙を始め てしまう。臨床に抢ける具体例として外来患者に おける尿中 Cotinine 測定の一症例を紹介する.

1 日10２0本の喫煙習慣があるこの患者は，喘 息発作により救急受診を繰り返した後，大発作に よるチアノーゼをおこし，緊急入院となった，入 院中，禁煙とともに症状が軽快し，患者の希望に よりニコレットを用いた禁煙指導を受けるが、症 状が無くなると再び喫煙を始め, 退院時には 1 日 5 本程度の喫煙状態となっていた。その後，医師 より何度も禁煙を钦められ，本人も禁煙している といっていたが, 平成 7 年には32回にものぼる救 急受診と 4 回の入院を繰り返し，禁煙はできなか った。 5 度目の退院時, 医師より厳しく禁煙をい われた後, 平成 8 年 1 月末, 尿中 Cotinine 測定を 依頼された。呼気中 $\mathrm{CO}$ 濃度は $5 \mathrm{ppm}$ 程度（CO アナライザー）であった。喫煙者では $10 \mathrm{ppm}$ 以

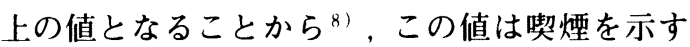
ほどのものではなかった. Fig. 4 にこの患者の尿 のクロマトグラムを示した，患者は禁煙している といっていたがFig. 4のように1428ng/ml（1739 Cotinine/Cr) の Cotinine が検出されており, $10 \mathrm{mg} /$ day 程度の Nicotine 搨取が示唆された. ニコチン ガムの処方はされていなかったので喫煙が疑われ 

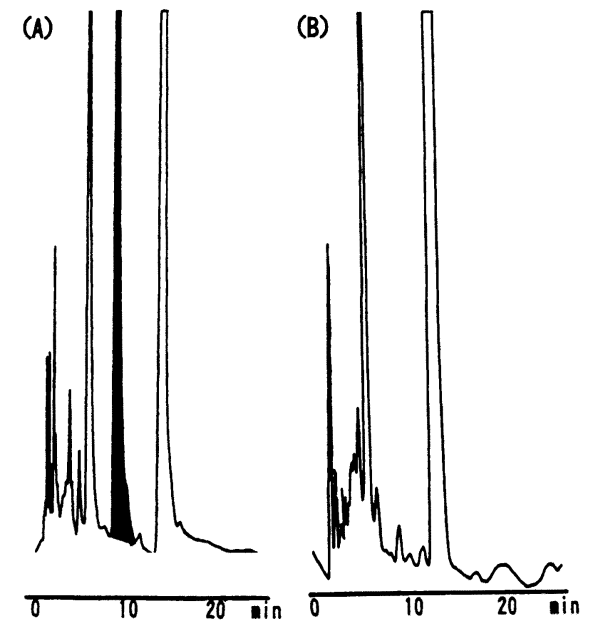

- Cotinine $1428 \mathrm{ng} / \mathrm{ml}$

Fig. 4. HPLC Chromatograms Obtained from Urine of an Asthma Patient

(A) on consulting, (B) on leaving the hospital

た。その後,この患者は喘息発作を何度かおこ し，測定 1 週間後に救急車で緊急入院となった. 入院時の血中 $\mathrm{Hb}-\mathrm{CO}$ は2.2\%であった。退院前 の尿中には Cotinine は検出されていなかった。 呼気中からは検出されず，尿中 Cotinine が検出 されたということは $\mathrm{CO}$ の半減期が数時間と短い のに比べ, Cotinine の半減期は約20時間 ${ }^{5)}$ と長い ことに起因しているものと思われる．この患者の ように喫煙が誘因で喘息発作が起こり入院治療の 後, 症状の軽快とともに本人に禁煙の意思がうす れ再び喫煙を始めてしまうような場合において， 尿中 Cotinineの測定は患者にとって禁煙を支援
し，再喫煙を防止する動機付けになるのではない かと思われる。

禁煙支援の一環として尿中 Cotinine を測定する ことが，今回紹介した症例のように患者の喫煙の 動機付けにおいてCO アナライザーにまさる禁煙 支援方法となりうることが示唆された．今後，禁 煙支援システムの手助けとなり，また，受動契煙 による Cotinine を測定できることで，家庭や職場 における間接的なタバコ煙の暴露が本人の疾患に 与える影響が推しはかれるように，今後更なる検 討をしていきたい。

\section{引用文献}

1) G. A. Kyerematen and E. S. Vesell, Drug Metab. Rev., 23, 3-7 (1991).

2) Peyton J., Wilson M. and Benowitz N. L., J. Chromatogr., 222, 61-70 (1981).

3) G. J. Knight, G. E. Palomoki, D. H. Lea and J. E. Haddow, Clin. Chem., 35, 10361040 (1989).

4) Curvall Margareta, Vala EK, Enzell CR, et al., Clin. Pharmacol. Ther., 47, $42-49$ (1982).

5) M. J. Jarris, Mutation Research, 222, 101110 (1989).

6) P. P. Rop, F. Grimaldi, C. Oddoze and A. Viala, J. Chromatogr., 612, 302-309 (1993).

7) 武田則昭, 實成文彦, 福永一郎他, 四国公衛誌, 38, 181-187 (1933).

8) 川根博司, からだの科学, 169, 54-57 (1993). 